\title{
Excited State Chemistry in the Free Stream of the NASA IHF Arc Jet Facility Observed by Emission Spectroscopy
}

\author{
Michael W. Winter ${ }^{1}$ \\ University Affiliated Research Center (UARC), NASA Ames Research Center, Moffett Field, CA 94035 \\ Dinesh K. Prabhu ${ }^{2}$ \\ ERC Inc., NASA Ames Research Center, Moffett Field, CA 94035
}

\begin{abstract}
Spectroscopic measurements of non-equilibrium emission were made in the free stream of the 60 MW Interaction Heating Facility at NASA Ames Research Center. In the visiblenear infra red wavelength region, the most prominent emission was from molecular $\mathrm{N}_{2}$, and in the ultra violet region, the spectra were dominated by emission from molecular NO. The only atomic lines observed were those of copper (an erosion product of the electrodes). The bands of the $1^{\text {st }}$ Positive system of $\mathrm{N}_{2}(\mathrm{~B} \rightarrow \mathrm{A})$ differed significantly from spectra computed spectra assuming only thermal excitation, suggesting overpopulation of the high vibrational states of the $B$ state of $N_{2}$. Populations of these high vibrational levels (peaking at $v_{\text {upper }}=13$ ) of the $\mathrm{N}_{2}$ B state were determined by scaling simulated spectra; calculations were performed for each upper vibrational state separately. The experimental-theoretical procedure was repeated for several radial positions away from the nozzle axis to obtain spatial distributions of the upper state populations; rotational symmetry of the flow was assumed in simulations. The overpopulation of the high vibrational levels has been interpreted as the effect of inverse pre-dissociation of neutral atoms in the $N_{2}$ A state, which populates the $N_{2} B$ state through a level crossing process at $\mathrm{v}_{\text {upper }}>\mathbf{1 0}$.
\end{abstract}

\section{Introduction}

$\mathrm{T}$ HE development and qualification of heatshield materials for high-speed atmospheric entries rely heavily on ground testing in high enthalpy plasma facilities such as the arc jets at NASA Ames Research Center (ARC). The Interaction Heating Facility (IHF) is one of several arc jets at NASA ARC used to simulate the aerodynamic heating that occurs for areas of the spacecraft that require thermal protection. Plasma diagnostic methods are necessary to improve understanding and better characterize the test conditions in these facilities.

In the plenum region of the arc heater, the gas is considered to be in thermal and chemical equilibrium, but upon expansion in the diverging section of the nozzle, the chemical composition and vibrational excitation of the gas is most appropriately viewed as frozen. A key parameter that characterizes the local thermodynamic state of the gas mixture is the specific total enthalpy, which is known to only a limited degree of certainty. The total enthalpy at any point in the flow is a sum of the kinetic, thermal, and chemical modes. Of particular interest is the energy store in the chemical mode. Optical methods are well suited for this purpose since they are non-intrusive and they do not modify the local state of the flow. In the present work, emission spectroscopic measurements, in combination with theoretical analyses, are made with the aim of determining number densities of atomic species. The analysis takes advantage of the non-equilibrium environment by closely investigating inverse pre-dissociation processes which are usually negligible in an equilibrium plasma, but may become dominant under non-equilibrium conditions.

\footnotetext{
${ }^{1}$ Research Scientist, University Affiliated Research Center UARC, UC Santa Cruz, NASA Ames Research Center, Building 230 - Mail Stop 230-3, Moffett Field, CA 94035, Michael.Winter@nasa.gov, AIAA member

${ }^{2}$ Senior Research Scientist, Aerothermodynamics Branch. Associate Fellow AIAA.
} 
The objectives of the present work are:

1. To obtain calibrated emission signatures of the free stream plasma and identify the major radiating species.

2. To interpret the non-equilibrium molecular radiation through inverse pre-dissociation processes to obtain information about ground state densities of the atoms involved in these processes with the final goal of getting estimates of the chemical component of enthalpy.

\section{Facility and Optical Set-up}

The 60 MW Interaction Heating Facility (IHF), one of several arc jet facilities at NASA Ames Research Center, is used to test and qualify spacecraft thermal protection materials in "flight-like" aerothermal environments. The IHF heater is a constricted arc design with an upstream anode, and a downstream cathode, which consists of 8 electrode disks. The working gases are injected throughout the constrictor tube and heated to very high temperatures by the arc column, which is established between the anode and the cathode (region 1 in Fig. 1). The magnitude of the temperatures achieved, hence the energy of the flow, depends on the input current, voltage, and flow rates. Following the cathode, there are 4 disks/segments through, which additional room temperature air (in the following referred to as "add air") can be injected to tailor the enthalpy of the working medium to the desired test value. This set of 4 segments (region 2 in Fig. 1) is referred to as the "plenum" in the present work. The working gas of appropriate enthalpy is then expanded through a convergent-divergent nozzle, and the test article is placed in the free jet (region 4 in Fig. 1).

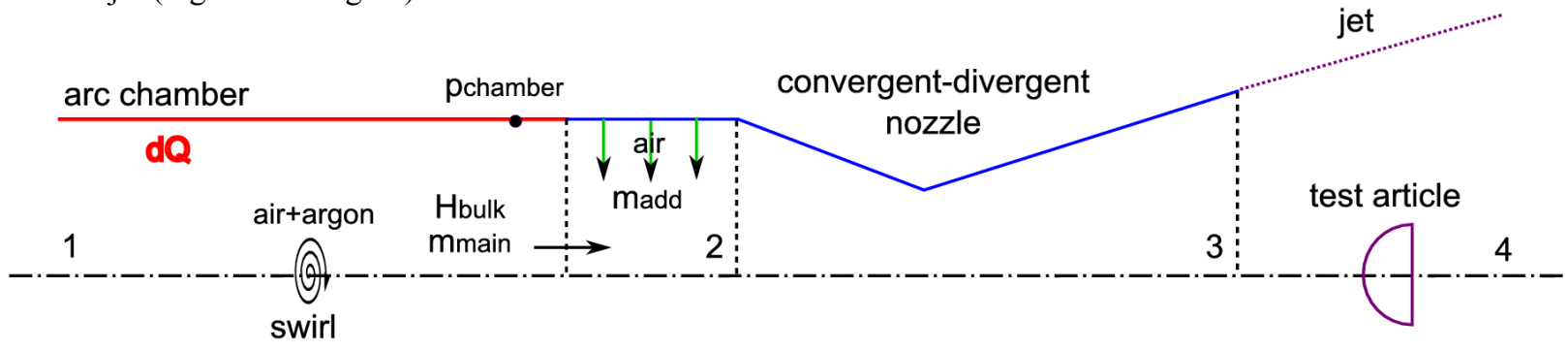

Figure 1. Sketch of the IHF working principle.

The operating conditions of the facility are mainly characterized by arc current and voltage, and the different mass flows (main air, add air and argon) yielding a chamber pressure and a bulk enthalpy derived from the balance of input power and cooling losses. Data were taken at low and high enthalpy heater conditions. However, analyzed results are currently only available for a high enthalpy condition at $21.6 \mathrm{MJ} / \mathrm{kg}$. Emission spectra in the plenum region of the heater, ${ }^{1}$ heat flux measurements with different calorimeters, ${ }^{2}$ two photon LIF measurements of atomic nitrogen and oxygen, ${ }^{3}$ and emission spectroscopy measurements in the free stream were carried out. The latter ones are described here. Table 1 specifies the arc heater settings.

Table 1. Arc heater settings for the high and low enthalpy test conditions.

\begin{tabular}{|c|c|c|c|c|c|c|c|}
\hline Condition & $\begin{array}{c}\text { Arc } \\
\text { Current } \\
(\mathbf{A})\end{array}$ & $\begin{array}{c}\text { Arc } \\
\text { Voltage } \\
(\mathbf{V})\end{array}$ & $\begin{array}{c}\text { Main-Air Mass } \\
\text { Flow Rate } \\
(\mathbf{g} / \mathbf{s e c})\end{array}$ & $\begin{array}{c}\text { Add-Air Mass } \\
\text { Flow Rate } \\
(\mathbf{g} / \mathbf{s e c})\end{array}$ & $\begin{array}{c}\text { Argon Mass } \\
\text { Flow Rate } \\
(\mathbf{g} / \mathbf{s e c})\end{array}$ & $\begin{array}{c}\text { Chamber } \\
\text { Pressure } \\
(\mathbf{k P a})\end{array}$ & $\begin{array}{c}\text { Bulk } \\
\text { Enthalpy } \\
(\mathbf{M J} / \mathbf{k g})\end{array}$ \\
\hline Low & 2000 & $3690-3720$ & 200 & 55 & 26 & 240 & 14.5 \\
\hline High & 6000 & 7300 & 740 & 55 & 54 & 886 & 21.6 \\
\hline
\end{tabular}

Data were acquired at a position 10 inches $(254 \mathrm{~mm})$ downstream of the nozzle exit covering a maximal wavelength range of $200 \mathrm{~nm}$ to $1000 \mathrm{~nm}$ with different spectrometers (Ocean Optics S2000, Echelle ME200+Pixis CCD, Acton SP300i+PImax CCD) in different wavelength resolutions. Table 2 lists the spectral characteristics of the different set-ups. The plasma on the generator axis at a distance of $2.1 \mathrm{~m}$ to the focusing spherical mirror $(\mathrm{f}=305 \mathrm{~mm})$ was imaged on a bifurcated optical fiber which allowed for simultaneous measurements of two channels. The f number of the fiber (numerical aperture $n_{A}=0.22$ ) was matched using an aperture between mirror and fiber. Figure 2 shows the optical set up. Radial profiles were obtained by inclining the focusing set-up thus measuring tilted lines of sight through the plasma beam characterized by the vertical offset to the center line. A total of six lines contained significant signal, measured at offsets of $3 \mathrm{~mm}, 59 \mathrm{~mm}, 92 \mathrm{~mm}$, $117 \mathrm{~mm}, 144 \mathrm{~mm}$ and $168 \mathrm{~mm}$. At higher offsets, the measured signal contained mainly noise. 


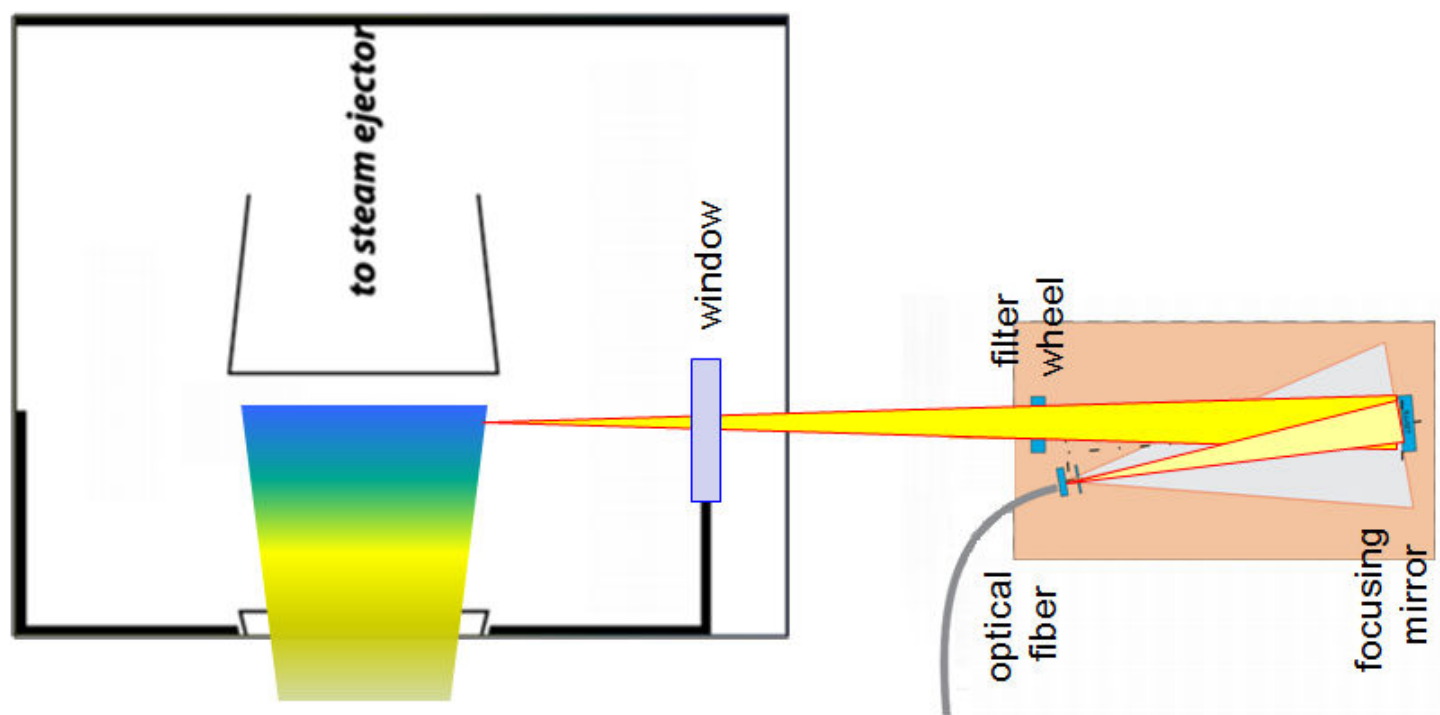

Figure 2: Sketch of the set up for emission spectroscopy measurements.

Table 2. Spectral characteristics of the different optical set-ups.

\begin{tabular}{|c|c|c|c|c|c|}
\hline Spectrometer & Grating & CCD & wavelength range & $\begin{array}{l}\text { pixel } \\
\text { resolution }\end{array}$ & FWHM \\
\hline $\begin{array}{l}\text { Ocean Optics } \\
\text { UV-VIS }\end{array}$ & $300 \mathrm{l} / \mathrm{mm}$ & Internal, 12 Bit & 200nm-1000nm* & $\sim 0.7 \mathrm{~nm}$ & $4.5 \mathrm{~nm}$ \\
\hline $\begin{array}{l}\text { Ocean Optics } \\
\text { UV }\end{array}$ & $1200 \mathrm{l} / \mathrm{mm}$ & Internal, 12 Bit & $200 \mathrm{~nm}-500 \mathrm{~nm}$ & $\sim 0.15 \mathrm{~nm}$ & $1.2 \mathrm{~nm}$ \\
\hline $\begin{array}{l}\text { Echelle } \\
\text { ME-200 }\end{array}$ & $\begin{array}{l}\text { Echelle }+ \text { order } \\
\text { sorting prism }\end{array}$ & $\begin{array}{l}\text { PI Pixis1024x1024, } \\
16 \text { Bit, } 13 \mu \mathrm{m} \times 13 \mu \mathrm{m}\end{array}$ & $200 \mathrm{~nm}-1200 \mathrm{~nm}$ & $0.02 \mathrm{~nm}$ & $\sim 0.15 \mathrm{~nm}$ \\
\hline Acton Sp230i & $150 \mathrm{~g} / \mathrm{mm}$ & $\begin{array}{l}\text { PImax } 1024 \times 256 \\
16 \text { Bit, } 26 \mu \mathrm{m} \times 26 \mu \mathrm{m}\end{array}$ & $200 \mathrm{~nm}-565 \mathrm{~nm}$ & $0.55 \mathrm{~nm}$ & $1.1 \mathrm{~nm}$ \\
\hline Acton Sp2 30i & $150 \mathrm{~g} / \mathrm{mm}$ & $\begin{array}{l}\text { PImax } 1024 \times 256 \\
16 \text { Bit, } 26 \mu \mathrm{m} \times 26 \mu \mathrm{m}\end{array}$ & $495 n m-860 n m$ & $0.55 \mathrm{~nm}$ & $1.1 \mathrm{~nm}$ \\
\hline
\end{tabular}

* nominal range up to $1700 \mathrm{~nm}$ but detector sensitivity dies out at $1000 \mathrm{~nm}$
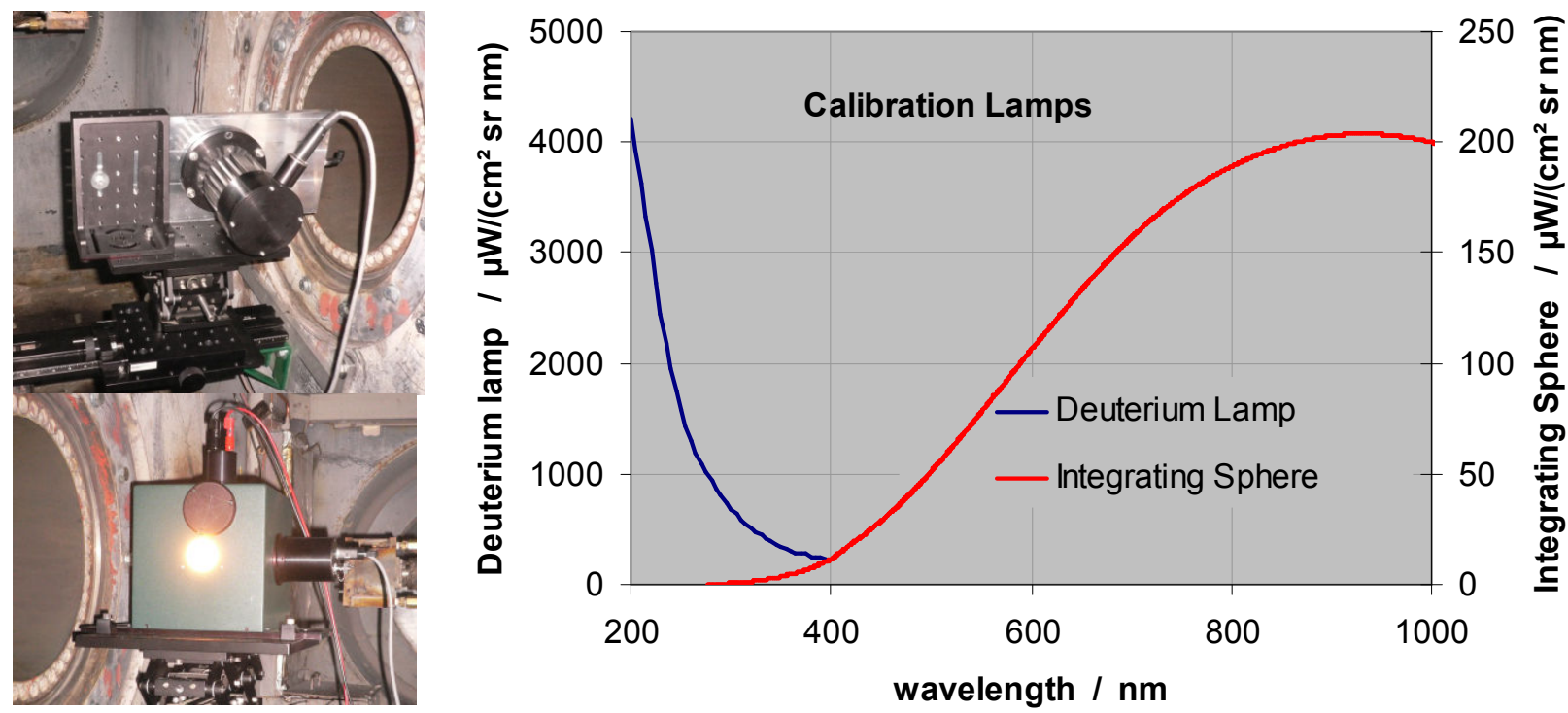

Figure 3: Calibration lamps in the IHF facility and manufacturer calibration data (Deuterium lamp shown for $1 \mathrm{~mm}$ spot diameter). 
The measurements were calibrated to absolute intensities using an integrating sphere and a Deuterium lamp, which were placed on the center axis of the facility. Although both lamps are calibrated to spectral radiance, the Deuterium lamp measurements were only used to extract the qualitative shape of spectral sensitivity and scaled to the values of the integrating sphere in the spectral overlap since the total measured intensity (and the manufacturer calibration data) of the Deuterium discharge strongly depends on the measured spot size. Even on axis, the spot size of $5 \mathrm{~mm}$ was much larger than the specified spot sizes for the calibration of the Deuterium lamp. The integrating sphere, however, shows a very good homogeneity across the open aperture of $20 \mathrm{~mm}$. The calibration data for these lamps are shown in Fig. 3.

At a first glance, the Echelle spectrometer set-up offers by far the best spectral resolution and the largest wavelength range although long integration times are required. However, the calibration turned out to be the least reliable. Although the spectrometer was calibrated according to the manufacturer's recommendations, the calibrated results show systematic disagreement with the ones from the other two set-ups (which agree fairly well with each other). Therefore, the Echelle results are only used for line identification purposes. The Ocean Optics spectrometers were easy to use and already configured for fiber fed input but required almost as long acquisition times as the Echelle spectrometer and provide only 12 Bit A/D conversion yielding a limited dynamic range. Therefore, a set-up with an Acton SP230i spectrometer used with a Princeton Instruments intensified PImax CCD camera was designed which offered the shortest acquisition times and highest dynamic range, though significantly reducing the spectral resolution. Since the spectral range of interest is more accurately known now, this set-up will be used with a higher spectral resolution by choosing a different grating in future tests. However, at the time these data were gathered, the spectral range chosen seemed necessary to cover as many vibrational levels as possible, and all spectra were recorded in low resolution.

\section{Theory/Modeling}

The gains made in modeling of high-temperature thermochemical nonequilibrium flowfields, and advances made in rapid and efficient numerical solvers for such models, have enabled the development of frameworks for analysis of arc-heated flows expanded using a nozzle. ${ }^{4}$ The analysis framework makes use of the fact that the geometry of test nozzles is well known, and that the nozzle-calorimeter combinations are usually fixed. Therefore, there is only a one-time investment in building grids required for numerical simulation; grid generation is usually a long-lead item in the computational process. The computational domain contains the plenum, the convergent-divergent nozzle, and the free jet. Since the nozzles are almost always underexpanded (i.e., $p_{\text {exit }}>p_{\text {test chamber }}$ ), the free jet is truncated in such a way as to allow imposition of supersonic extrapolation at the boundaries. The calorimeter/test article is considered as an integral part of the computational domain. Such an approach allows for consideration of flow nonuniformities (in either enthalpy, and/or mass flux). In order to speed up the analysis process, axial symmetry is assumed, thus reducing the problem from three dimensions to two. Although the analysis process has been streamlined, there are several uncertainties and unanswered questions regarding the flow, especially the radial distribution of enthalpy (i.e., enthalpy non-uniformity) in the jet.

In the present effort, a volume grid has been constructed for the 13-inch nozzle of the IHF and free jet without any calorimeter or test article. The axisymmetric version of the CFD code $D P L R^{5}$ solves the equations governing the temporal development (to steady state) of a flow consisting of 12-species $\left(\mathrm{N}_{2}, \mathrm{O}_{2}, \mathrm{NO}, \mathrm{NO}^{+}, \mathrm{N}_{2}^{+}, \mathrm{O}_{2}^{+}, \mathrm{N}, \mathrm{O}, \mathrm{N}^{+}, \mathrm{O}^{+}\right.$, $\mathrm{e}^{-}, \mathrm{Ar}$ ) in thermochemical nonequilibrium. The facility measured flow rates (of air and argon), and arc column pressure are used to estimate the bulk enthalpy of the arc-heated flow in the plenum section. Using an in-house code, NOZZLE_THROAT_CONDITIONS, flow non-uniformities in enthalpy and mass flux are considered (Gaussian distributions are considered based on nullpoint surveys of the free jet). Further details of the computational process/procedure can be found in Ref. 4 .

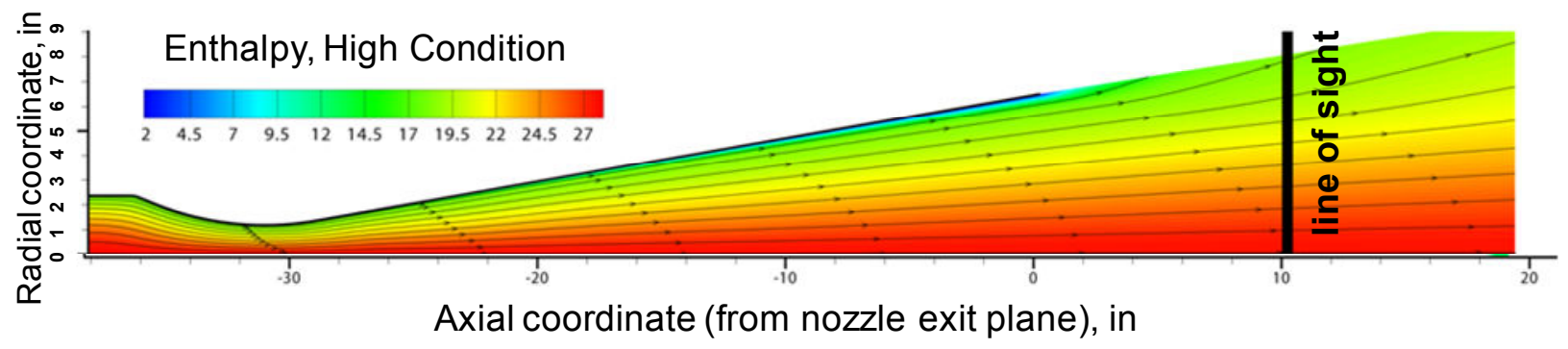

Figure 4. Numerically computed enthalpy distribution in plenum, nozzle and free stream, of the IHF. 
From the converged solution, profiles of the translational/rotational and vibro-electronic temperatures, and number densities of all the constituent species are extracted at a distance of 10 inches from the nozzle exit plane as shown in Fig. 5. The simulation shows a rather flat profile of translational temperature between $2000 \mathrm{~K}$ and $2150 \mathrm{~K}$ for radial positions less than $13 \mathrm{~cm}$ and drops down rapidly for higher radial positions. In the same region, the vibrational temperature has a more distinct profile with a maximum value of $3200 \mathrm{~K}$ which flattens out at high radial position at values about $2700 \mathrm{~K}$. Oxygen is found to be almost completely dissociated, nitrogen dissociation has a distinct profile peaking on axis with a value of roughly $40 \%$. The ionization fraction is low with maximum values on axis of about $0.01 \%$.

The extracted profiles are considered to be the simulated line of sight, and the data are used in the NEQAIR 2009 V6.6 which is a line-byline spectroscopic code with onedimensional transport of radiative intensity. It computes the emission and absorption of atoms $(\mathrm{N}, \mathrm{O}, \mathrm{H}, \mathrm{C}, \mathrm{He})$ and molecules $\left(\mathrm{N}_{2}, \mathrm{~N}_{2}^{+}, \mathrm{NO}, \mathrm{O}_{2}, \mathrm{H}_{2}\right.$, $\mathrm{CO}, \mathrm{C}_{2}, \mathrm{CN}$ ) as well as bound-free and free-free continuum radiation caused by interactions of electrons with neutral and ionized atomic species. Line broadenings due to Doppler, Stark, resonance, and collisional mechanisms as well as the natural line width realized through Voigt broadening are included and an additional Voigt broadening can be applied to account for instrument broadening. Radiative transport is computed along a line-of-sight as a series of one-dimensional cells - a tangent slab approximation. In absence of an individual electron temperature in the two temperature model used in DPLR, the vibrational temperature is used for electronic excitation.

Principal molecular band systems considered in this work are the $1^{\text {st }}$ and $2^{\text {nd }}$ positive systems of $\mathrm{N}_{2}$, the $1^{\text {st }}$ negative system of $\mathrm{N}_{2}{ }^{+}$, the $\gamma, \beta, \delta$, and $\varepsilon$ systems of NO. High-resolution spectra were computed using NEQAIR for these band systems and were convolved with the experimentally determined instrument function to produce synthetic spectra for comparison against the measurements.
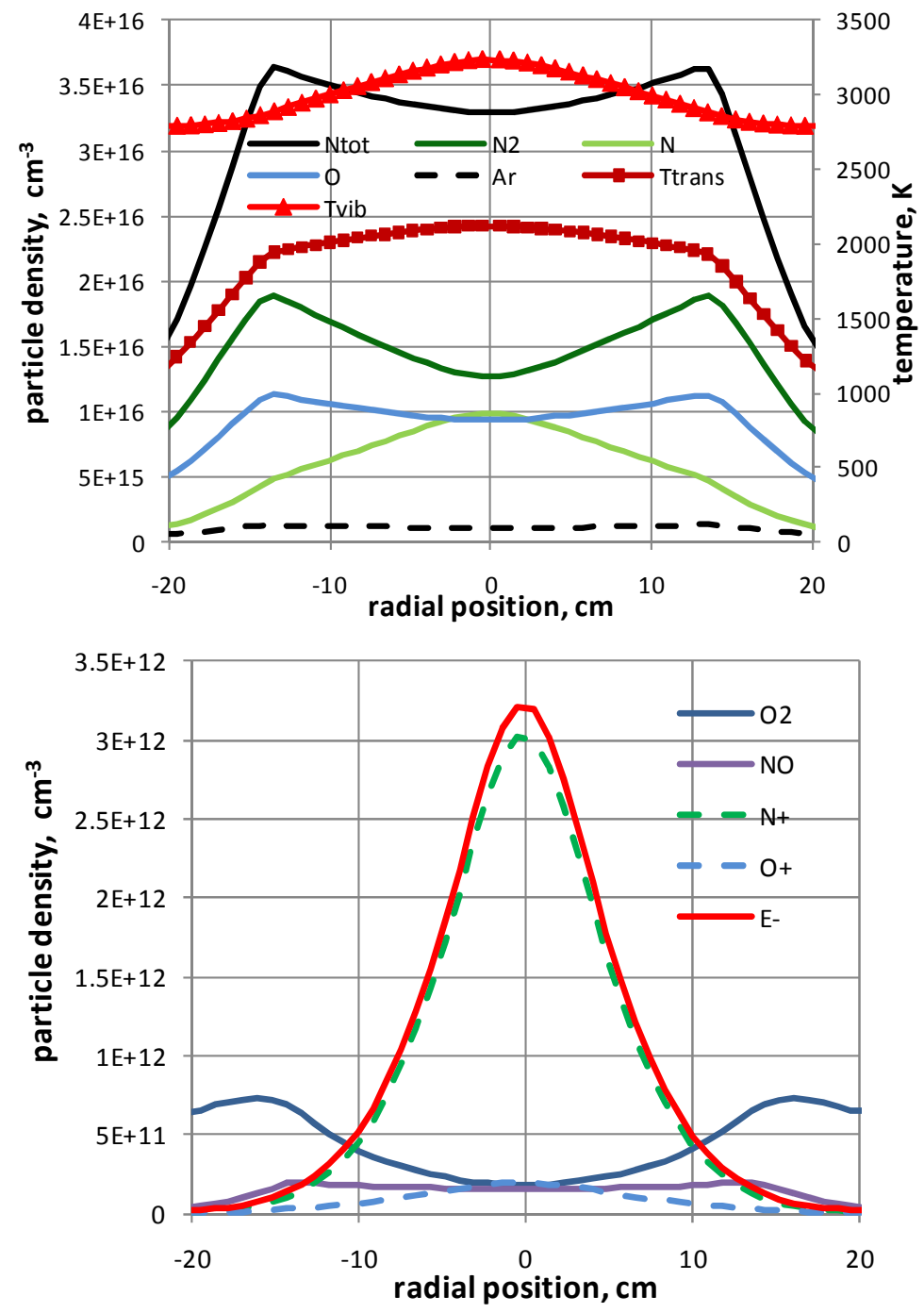

Figure 5. Temperature and particle density profiles along the center line of sight at a distance of $\mathbf{1 0}$ inches to the nozzle exit, extracted from the DPLR simulation.

To help with the interpretation of the measured data, NEQAIR was modified to provide the option of separate computation for an individual upper vibrational state (i.e. only one specific upper vibrational quantum number for a given electronic transition to all possible lower ones) and to write out the sum of all upper state particle densities involved in the computed spectrum. 


\section{Experimental Data and Analysis}

The spectra were dominated by the emission of different NO systems in the UV and by the emission of the $1^{\text {st }}$ Positive system of $\mathrm{N}_{2}$ (B-A transition) in the visible (VIS) and near infrared (NIR). In both spectral regions, the spectral characteristics were effectively the same for the high and low enthalpy conditions but differed in intensity by about one order of magnitude as shown in Fig. 6.

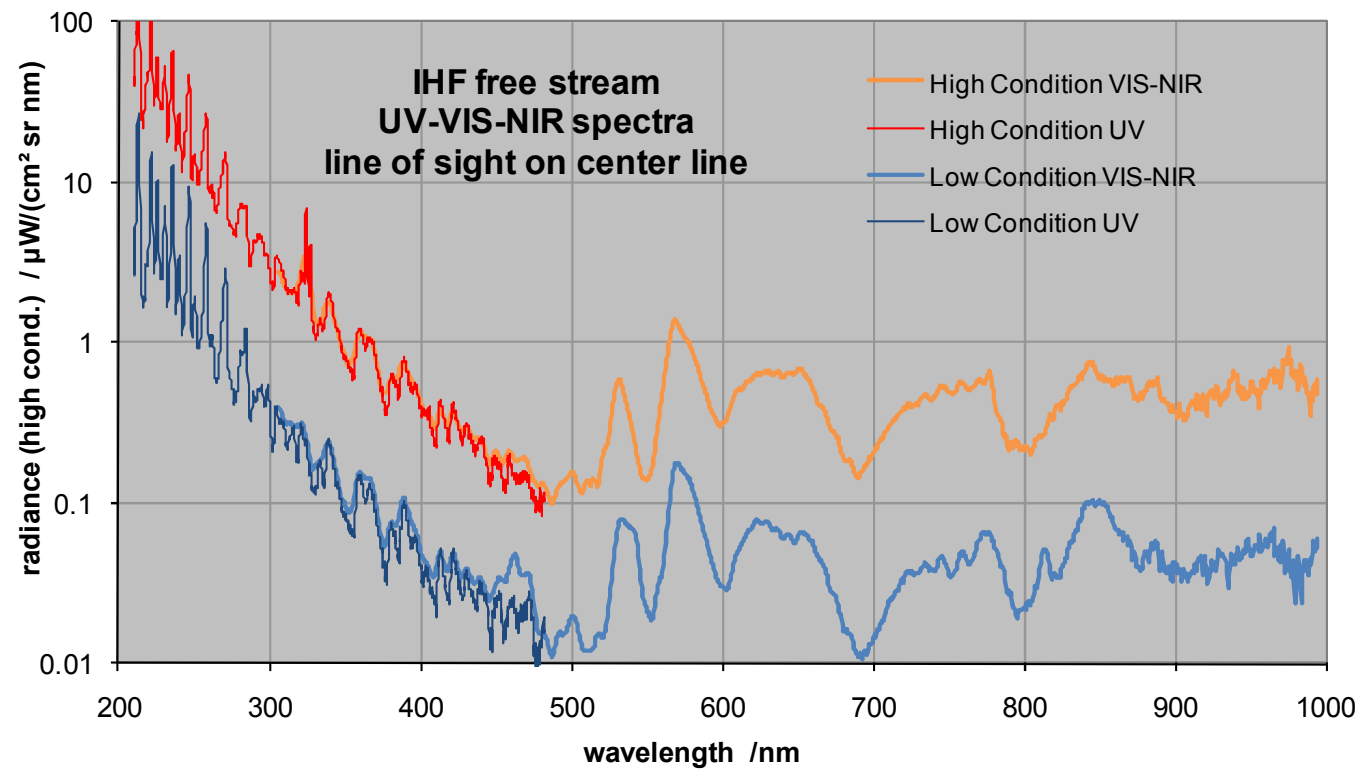

Figure 6: Spectra at low and high condition measured with the Ocean Optics spectrometers.

In a first approach, simulated spectra were generated by using the DPLR solution along the lines of sight as input for NEQAIR. The measured data are substantially different than the prediction, both in intensity and shape. Therefore, the simulations were repeated for each radiating species separately to be able to scale the different spectral components individually. In the UV region, the center line spectra could be rebuilt with the CFD vibrational temperature used as the electronic excitation temperature, only if overpopulation factors of about 6 orders of magnitude were applied to match experimental and simulated NO radiation as demonstrated in Fig. 7.

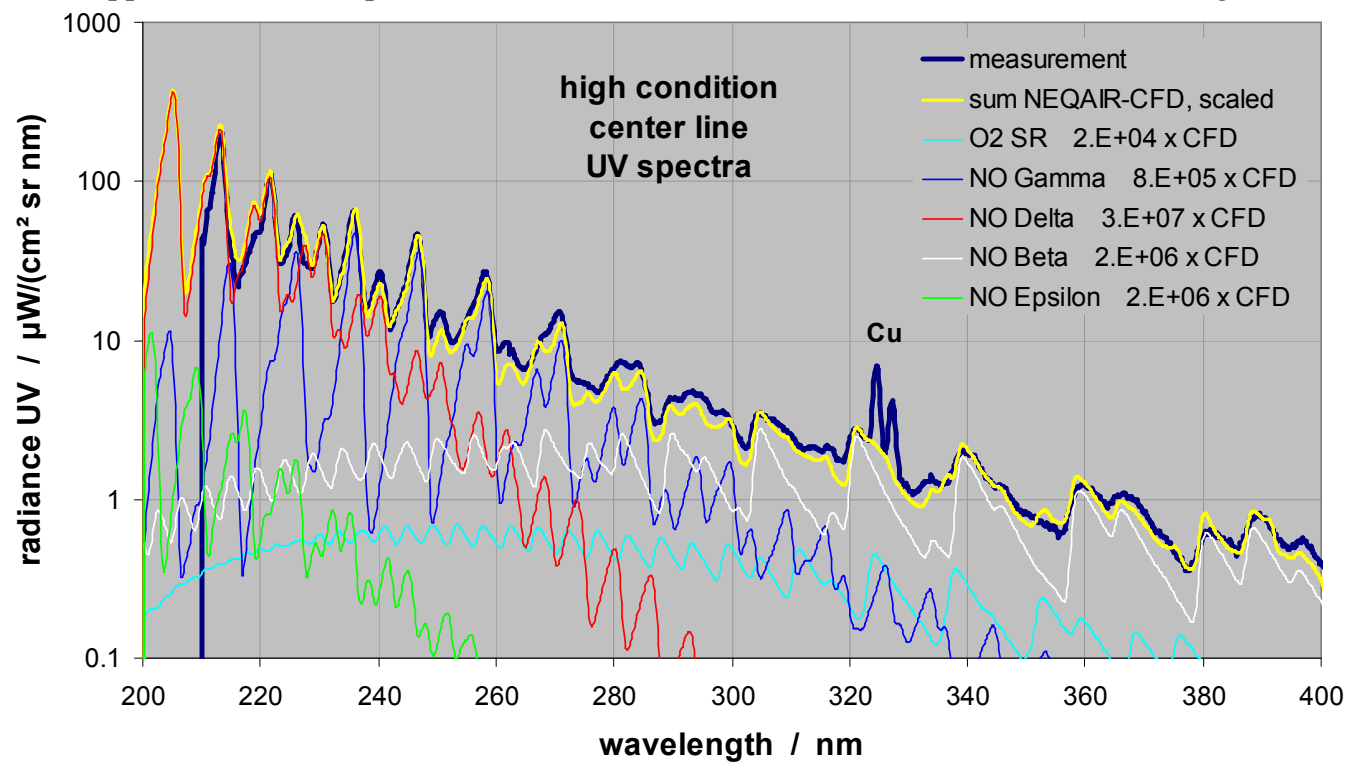

Figure 7: Measured UV spectrum at high condition and scaled CFD simulation.

To account for this overpopulation, excitation temperatures on the order of $9000 \mathrm{~K}$ would be needed instead of the $3200 \mathrm{~K}$ temperature predicted by CFD. Similar temperature values have already been reported in earlier 
investigations of arc-jet flows ${ }^{7,8}$ and might be attributed to an insufficient representation of the non-equilibrium environment by the two-temperature model used in DPLR. However, in comparison to the other NO systems, an overpopulation of the NO C state remains even if the electronic excitation temperature is adopted. This indicates the dominance of inverse pre-dissociation processes as successfully introduced by Chul Park ${ }^{7}$ for the interpretation of similar data obtained in the NASA Ames Aero Heating Facility (AHF) in Refs. 8, 9, and 10. Future analysis of the spectra will focus on this topic. Figure 7 displays the UV spectrum on the center line measured with the Ocean Optics spectrometers and scaled simulated emission on a logarithmic scale. In the VIS/NIR region between 500nm and $900 \mathrm{~nm}$, the spectrum is dominated by emission from the $\mathrm{N}_{2} 1^{\text {st }}$ Positive system. The measured spectra from different tests at the same condition do agree quite well even if measured with different spectrometers as shown in Fig. 8 for the Ocean Optics spectrometer and the Acton SP300i/PImax combination. However, the simulation based on Boltzmann populations for the rotational and vibrational excitation does not even qualitatively fit the measured data as shown in the same figure. To fit the spectra at low vibrational quantum numbers, an overpopulation factor of 2300 is required which, if interpreted as difference in electronic excitation, corresponds to an excitation temperature of approximately $4200 \mathrm{~K}$. This value is significantly lower than the temperature obtained from NO which indicates that part of the NO overpopulation might also be related to excited state chemistry if the electronic excitation temperatures of the different molecules are believed to be close to each other and to the electron temperature.

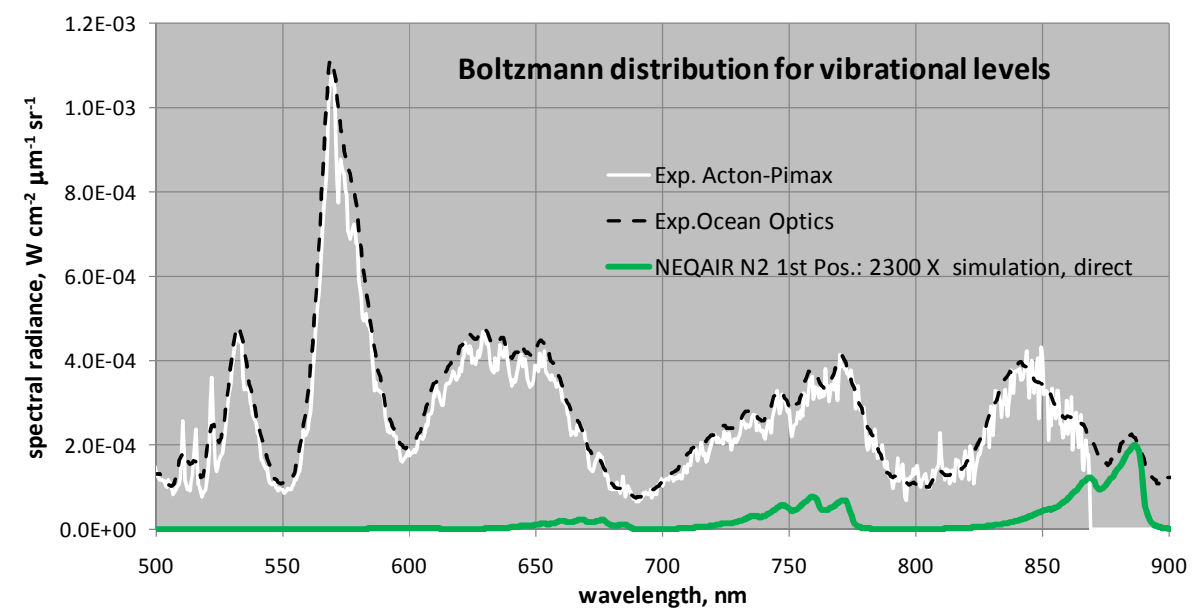

Figure 8: Measured VIS/NIR centerline spectra at high condition and scaled CFD simulation.

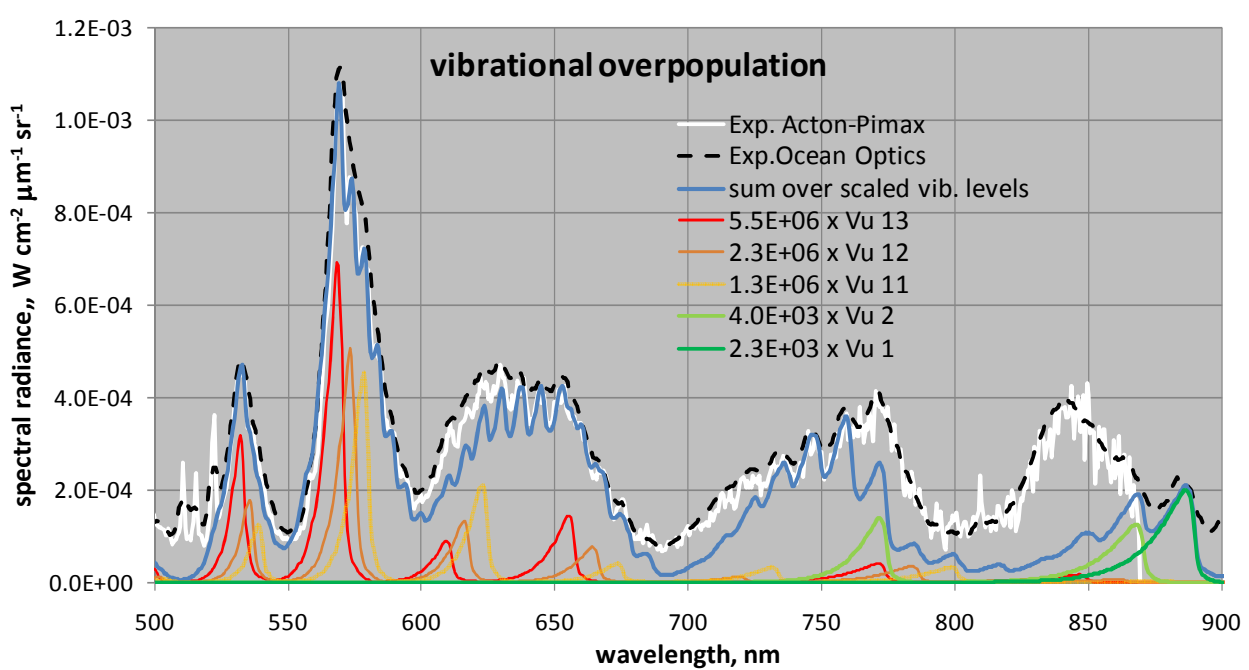

Figure 9: Measured VIS/NIR centerline spectra at high condition and scaled CFD simulation with modified $\mathbf{N}_{2}$ B state vibrational populations for selected levels.

However, if the theoretical spectra are computed separately for each upper vibrational quantum number to all allowed lower levels and if these spectra are appropriately scaled and summed, the spectrum below $800 \mathrm{~nm}$ can be reasonably well matched as shown in Figure 9. As a general rule for the scaling process, the sum over all vibrational 
levels was not allowed to exceed the measured spectrum at any wavelength. Best agreement was achieved for wavelength regions which are dominated by high vibrational quantum numbers (i.e. between $520 \mathrm{~nm}$ and $600 \mathrm{~nm}$ ). The highest disagreement (and therefore the highest uncertainty of the scaling factors) is seen in wavelength regions dominated by the emission due to low vibrational quantum numbers. The emission of vu 0 was outside the measured wavelength range.

Very similar data for the $\mathrm{N}_{2} 1^{\text {st }}$ Positive system were obtained by Gessman et al. in an equilibrium nitrogen flow generated by a $50 \mathrm{~kW}$ Inductively Coupled Plasma Torch which was rapidly cooled and therefore artificially brought to non-equilibrium. ${ }^{11}$ These spectral data were successfully rebuilt when measured overpopulation factors of the different vibrational levels of the $\mathrm{N}_{2}$ B system were applied to the SPECAIR code for spectral simulation. ${ }^{12}$ Finally, this overpopulation could be explained by inverse pre-dissociation of $\mathrm{N}$ atoms into the $\mathrm{N}_{2} \mathrm{~B}$ state using a collisional radiative model. ${ }^{12,13}$

In this work, there is not really a reliable equilibrium state given against which overpopulation factors can be defined. Instead, total upper state densities were determined. As mentioned previously, NEQAIR was modified to write out the generating upper state population for each spectrum for a specific upper vibrational quantum number.

If the scaling factors for the spectra are applied to these upper state densities, a measured upper state population density for each vibrational quantum number is obtained. This number no longer depends on the input quantities which were used to generate the original spectrum and are therefore independent of temperature or equilibrium assumptions. As a check, NEQAIR simulations with different input temperatures were scaled to the same experimental spectrum and yielded the same upper state densities.

In the NEQAIR simulation based on the CFD solution, the upper vibrational levels are populated through a Boltzmann distribution. The population densities are decreasing with vibrational quantum number in an exponential manor as shown in Fig. 10 a). Here the population densities are integrated along the simulated line of sight, therefore given in the slightly unconventional unit $\mathrm{cm}^{-2}$. However, this convention becomes handy for further processing of the experimental data. The population of high vibrational levels is very low, almost $100 \%$ of the population of the electronic state can be found at vibrational quantum numbers lower than $\mathrm{v}_{\mathrm{u}} 7$.

The measured vibrational population decreases from high values at low vibrational quantum numbers up to $v_{u} 7$ but starts increasing again with maximum values $\mathrm{v}_{\mathrm{u}} 13$ as shown in Fig. $10 \mathrm{~b}$ ). Almost half of the measured population density of the electronic state (admittedly not including $\mathrm{v}_{\mathrm{u}} 0$ and 1) can be found in levels with $\mathrm{v}_{\mathrm{u}}>7$. As discussed earlier, the measured data are considered less reliable for lower vibrational quantum numbers, therefore

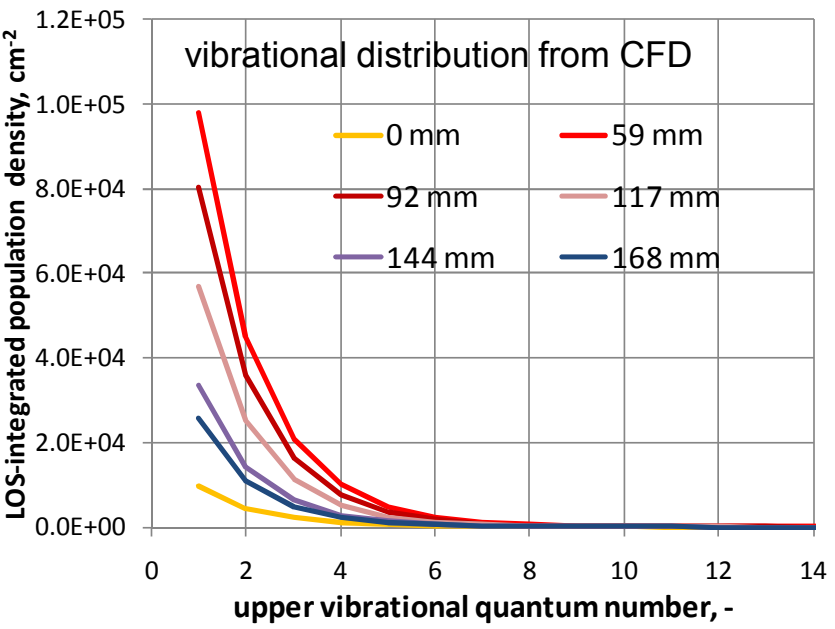

a)

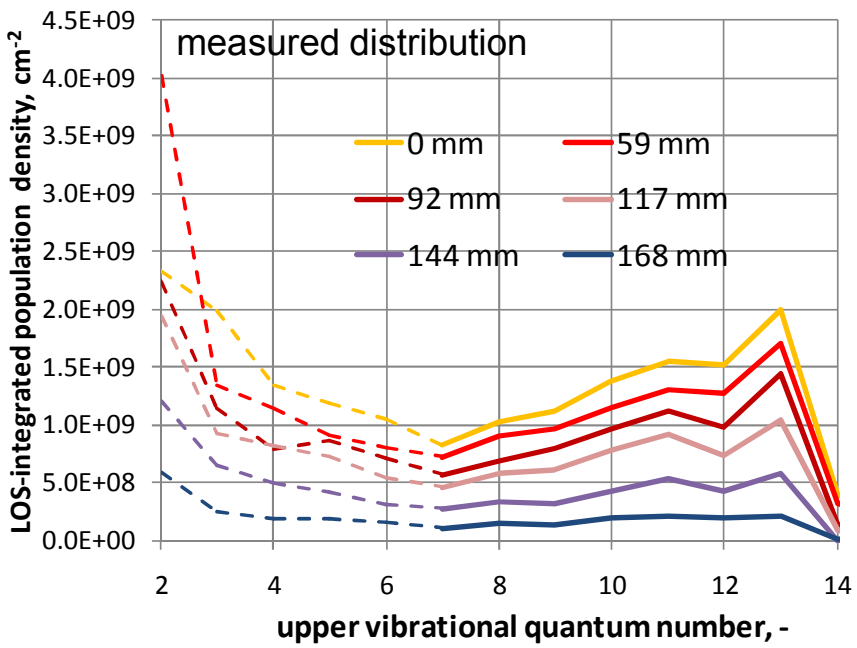

Figure 10: Population densities of different vibrational levels of the $\mathrm{N}_{2}$ B state based on a) CFD simulation and Boltzmann distribution and b) LOS integrated measurements. 
These values still represent an integration along the corresponding line of sight. To determine local values, a simplified Abel-inversion was applied, assuming rotational symmetry of the plasma beam. If each measurement is interpreted as an average over a ring with the inner diameter assumed to be the offset value on the generator axis as illustrated in Fig. 12 for 4 measurement positions, a rather simple system of linear equations can be formulated. If the outermost line of sight is interpreted as its own ring with constant population densities, the system for 4 lines of sight reads as:

$$
\begin{array}{lll}
I_{3, \text { int }}=I\left(r_{3}\right) * L_{3}\left(r_{3}\right) & \\
I_{2, \text { int }}=I\left(r_{3}\right) * L_{2}\left(r_{3}\right) & +I\left(r_{2}\right) * L_{2}\left(r_{2}\right) & \\
I_{1, \text { int }}=I\left(r_{3}\right) * L_{1}\left(r_{3}\right) & +I\left(r_{2}\right) * L_{1}\left(r_{2}\right) & +I\left(r_{1}\right) * L_{1}\left(r_{1}\right) \\
I_{0, \text { int }}=I\left(r_{3}\right) * L_{0}\left(r_{3}\right) & +I\left(r_{2}\right) * L_{0}\left(r_{2}\right) & +I\left(r_{1}\right) * L_{0}\left(r_{1}\right)
\end{array}
$$

and can even be solved recursively.

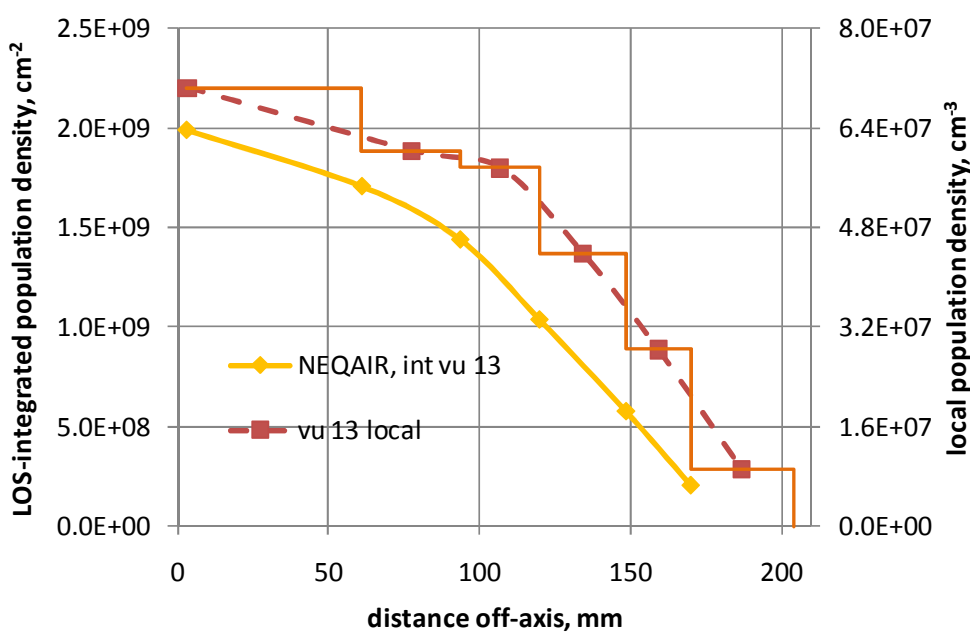

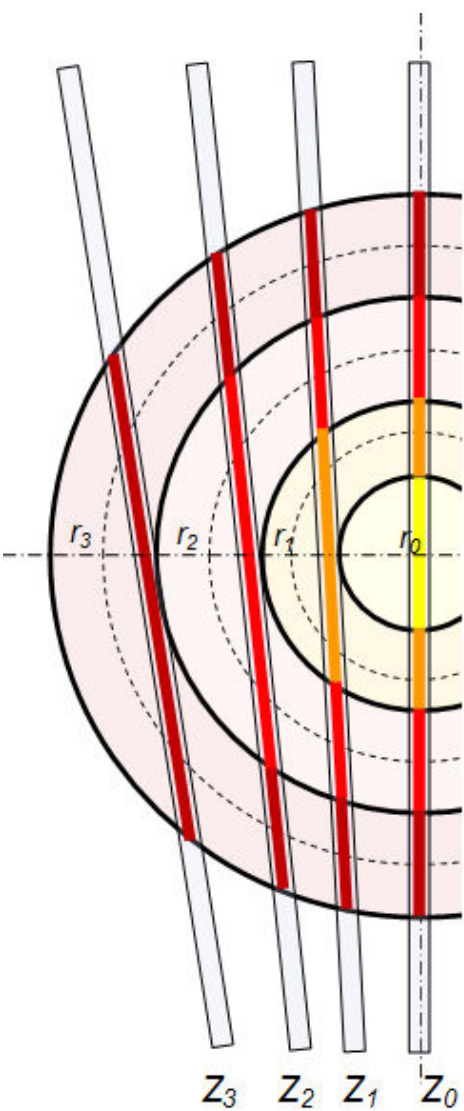

Figure 12: Detection geometry for 4 lines of sight and illustration of simplified Abel-inversion.

Figure 11: Results of the simplified Abel-inversion at the example of vu 13.

In Fig. 11, the results of this method are illustrated for the example of $v_{u} 13$. Each local value represents the average between the offset values of two neighboring lines of sight. A refinement could be reached by assuming a continuous change between two radial values (the first approach being a linear distribution) instead of a simple average. Figure 13 shows the local results from this reconstruction and a simple averaging by dividing through the corresponding line of sight for comparison purposes. As mentioned before, during the experiments, six lines of sight were measured.
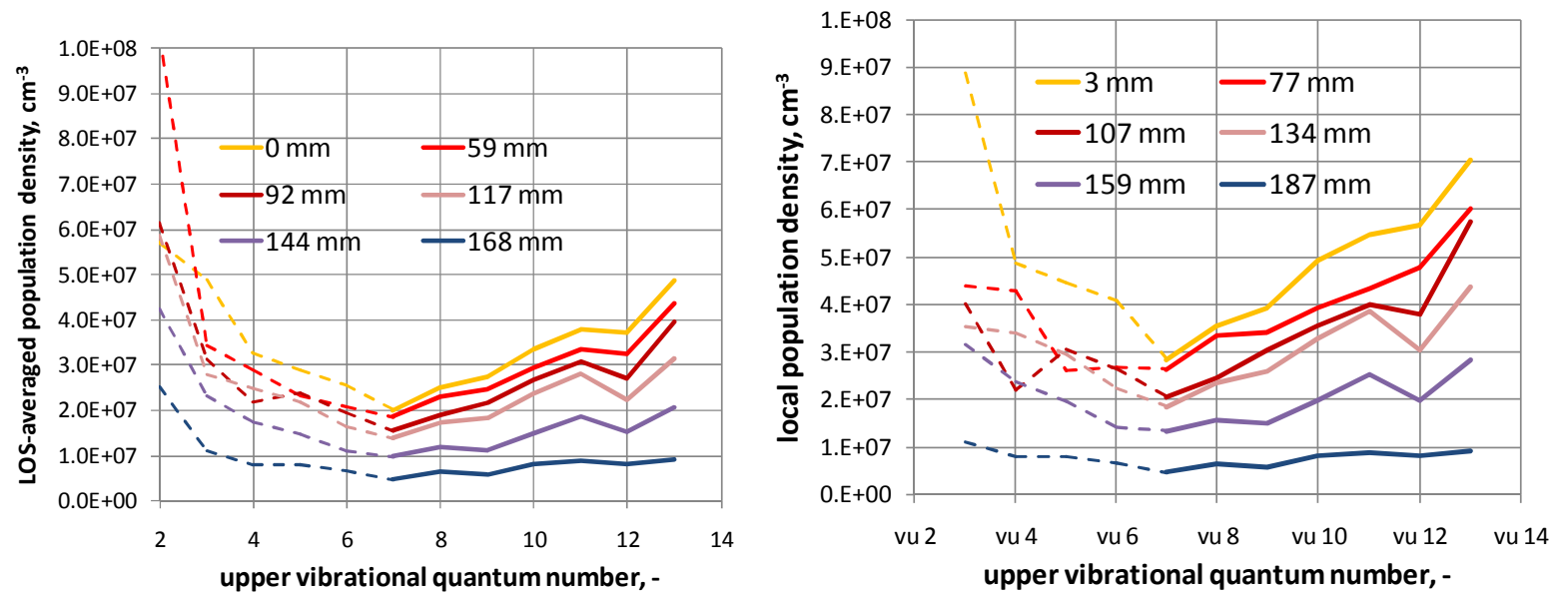

Figure 13: Measured population densities of different vibrational levels of the $\mathrm{N}_{2} \mathrm{~B}$ state a) averaged over line of sight b) local values after simplified Abel-inversion. 
The emission of nitrogen molecules due to excited state chemistry also appears in afterglows such as the LewisRayleigh afterglow. ${ }^{14}$ One major process is the inverse pre-dissociation of ground state atoms (N4S) into excited molecular states of nitrogen. Due to the quantum mechanical selection rules, the ground state atoms can only form the $\mathrm{X}^{1} \Sigma_{\mathrm{g}}{ }^{+}, \mathrm{A}^{3} \Sigma_{\mathrm{u}}{ }^{+}, \mathrm{A}^{, 5} \Sigma_{\mathrm{g}}^{+}$, and ${ }^{7} \Sigma_{\mathrm{u}}{ }^{+}$ states of which the latter one is essentially repulsive ${ }^{16}$. These states (in particular $\mathrm{N}_{2} \mathrm{~A}^{, 5} \Sigma_{\mathrm{g}}^{+}$) then, through collisions and/or level crossing processes, may populate preferred vibrational levels of other states such as $\mathrm{N}_{2} \mathrm{~B}^{3} \Pi_{\mathrm{g}}$ and $\mathrm{N}_{2} \mathrm{~B}^{3}{ }^{3} \Sigma_{\mathrm{u}}{ }^{+}$which are the upper states of dominant radiative transitions such as the $\mathrm{N}_{2}$ $1^{\text {st }}$ Pos. system $\left(\mathrm{N}_{2} \mathrm{~B}^{3} \Pi_{\mathrm{g}} \rightarrow \mathrm{N}_{2} \mathrm{~A}^{3} \Sigma_{\mathrm{u}}^{+}\right)$or the $\mathrm{N}_{2}$ afterglow system $\left(\mathrm{N}_{2} \mathrm{~B}^{3} \Sigma_{\mathrm{u}}^{+} \rightarrow \mathrm{N}_{2} \mathrm{~B}^{3} \Pi_{\mathrm{g}}\right)$. Predissociation and level crossing into the $N_{2} B^{3} \Pi_{g}$ state is known to preferably populate $\mathrm{v}_{\mathrm{u}} 13 .{ }^{15}$ For the population of lower vibrational levels, different explanations are given e.g. by vibrational relaxation to collisional population from other electronically excited states (e.g. collisional population of $\mathrm{N}_{2} \mathrm{~B}^{3} \Pi_{\mathrm{g}}, \mathrm{v}_{\mathrm{u}}=0-2$ from $\mathrm{N}_{2} \mathrm{~A}^{3} \Sigma_{\mathrm{u}}{ }^{+}, \mathrm{v}_{\mathrm{u}}=7-9$ ), or three body recombination

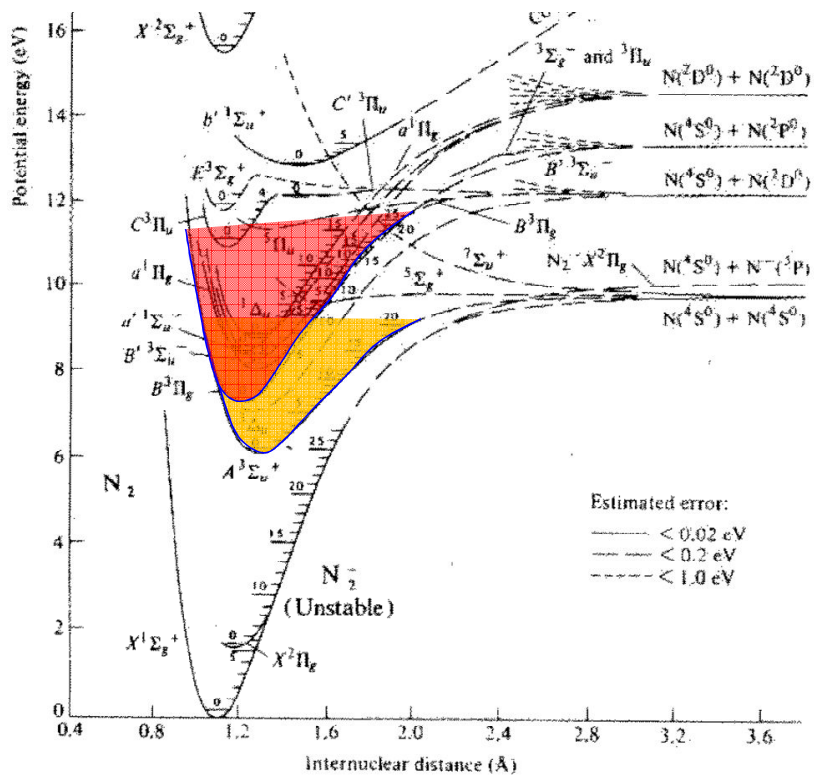

Figure 14: Potential energy diagram for $\mathbf{N}_{2}$ compiled by F.R. Gilmore. ${ }^{17}$ of atomic nitrogen. ${ }^{14}$

The level crossing processes have been investigated by Partridge et al. ${ }^{16}$ and rate constants for recombination of $\mathrm{N}$ atoms into different electronic states of $\mathrm{N}_{2}$ were given. A comparison of the potential curves for the different electronic states derived in that work as presented in Fig. 15 shows that a level crossing from the $\mathrm{N}_{2} \mathrm{~A}^{, 5} \Sigma_{\mathrm{g}}{ }^{+}$state to the $\mathrm{N}_{2} \mathrm{~B}^{3} \Pi_{\mathrm{g}}$ state can only occur into vibrational levels between $\mathrm{v}_{\mathrm{u}}>10$, the higher vibrational levels showing a larger potential overlap equivalent to higher rates.
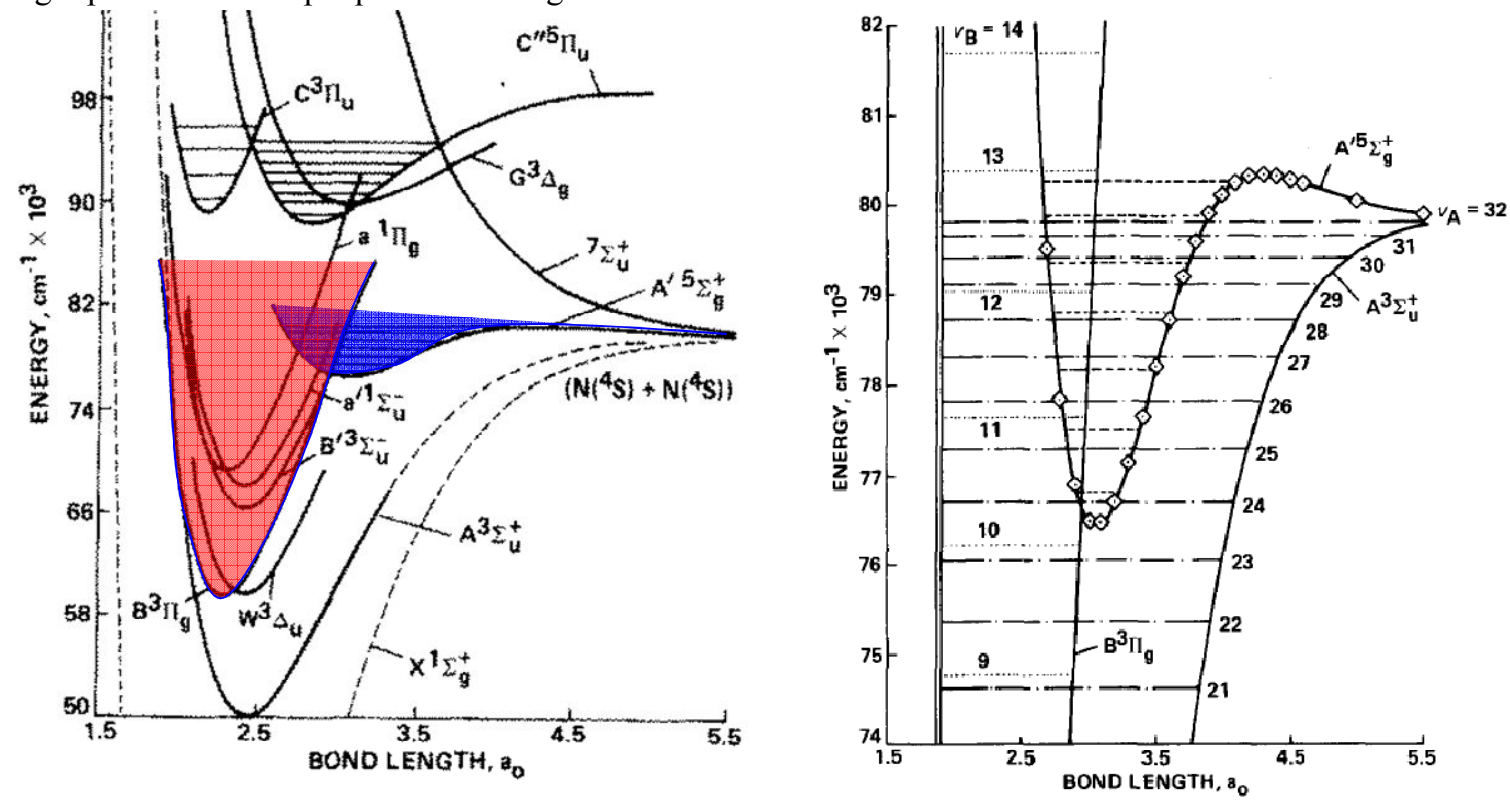

Figure 15: Potential crossing between the $N_{2} A^{, 5} \Sigma_{g}^{+}$, and $N_{2} B^{3} \Pi_{g}$ states as given in Ref. [16].

In the experimental data, no significant contributions of vibrational levels higher than $\mathrm{v}=13$ could be found with increasing upper state populations from $\mathrm{v}=10$ towards $\mathrm{v}=13$. These correlations are interpreted as a clear indication for the inverse pre-dissociation through the $\mathrm{N}_{2} \mathrm{~A}^{, 5} \Sigma_{\mathrm{g}}^{+}$state being a dominant process for the molecular radiation at 
the measured conditions. To further interpret these results, the sum of all populating and depopulation processes for the $\mathrm{N}_{2}$ B state are to be investigated:

- Thermal/vibrational excitation through electron collisions (both populating and depopulating) which requires knowledge of $\mathrm{T}_{\mathrm{el}}, \mathrm{T}_{\text {trans }}, \mathrm{T}_{\mathrm{vib}}, \mathrm{n}_{\mathrm{el}}, \mathrm{n}_{\mathrm{N} 2}$

- The major process for radiative depopulation goes to the $\mathrm{N}_{2}$ A state $\left(\mathrm{N}_{2} 1^{\text {st }}\right.$ Pos. System), the main population comes from the $\mathrm{N}_{2} \mathrm{C}$ state $\left(2^{\text {nd }}\right.$ Pos. System).

- Level crossing processes to other excited states

- Quenching due to heavy particle collisions

The following assumptions seem reasonable:

- Thermal/vibrational excitation of the high vibrational levels is negligible which means that knowledge of $\mathrm{T}_{\mathrm{el}}$ or $\mathrm{T}_{\mathrm{vib}}$ is not necessarily required if the analysis is restricted to these levels.

- The major radiative processes can be covered through measurement of $\mathrm{N}_{2} 1^{\text {st }}$ and $2^{\text {nd }}$ Pos. systems.

- Vibrational relaxation can be covered by integrating over the high vibrational levels or/and extrapolation of the measured levels to the lower ones through an appropriate fit function.

- The upper and lower bound for quenching can be estimated by no quenching and full quenching as a zero order approach (i.e. every collision depopulates the excited state).

- Due to the large difference in population densities between the $\mathrm{N}_{2} \mathrm{~B}$ state and the $\mathrm{N}$ ground state, inverse pre-dissociation will dominate and pre-dissociation can be neglected.

For a zero order approach, this leaves as unknowns the rates of level crossing processes and the heavy particle quenching with the assumption of no quenching as a lower bound. If the rate coefficients for the inverse predissociation processes are known, a the lower bound for the nitrogen atom particle densities can be derived from balancing the measured $\mathrm{N}_{2} 1^{\text {st }}$ Positive radiation (or better the sum over the scaled simulation for the vibrational levels under investigation) divided by $h v$ with the inverse pre-dissociation coefficient multiplied by the square of the nitrogen ground state density. Similar processes can be formulated for $\mathrm{NO}^{7}$ giving access to the product of $([\mathrm{N}][\mathrm{O}])$ but the measured data have not been evaluated to that extent.

Furthermore, the CFD solution is considered to provide sufficiently correct translational temperature, plasma velocity and pressure. The temperature and velocity show sufficient agreement with Twophoton Atom Laser Induced Fluorescence (TALIF) measurements $^{3}$ for the low enthalpy conditions and slightly lower temperature and velocity for the high enthalpy case as shown in Fig. 16. Pressure is usually in good agreement with probe measurements. ${ }^{2}$ This means that the gas dynamic state of the plasma is defined and the total number of particles is known. Therefore, an additional equation to either validate the data or estimate missing rate coefficients is available for further analysis.

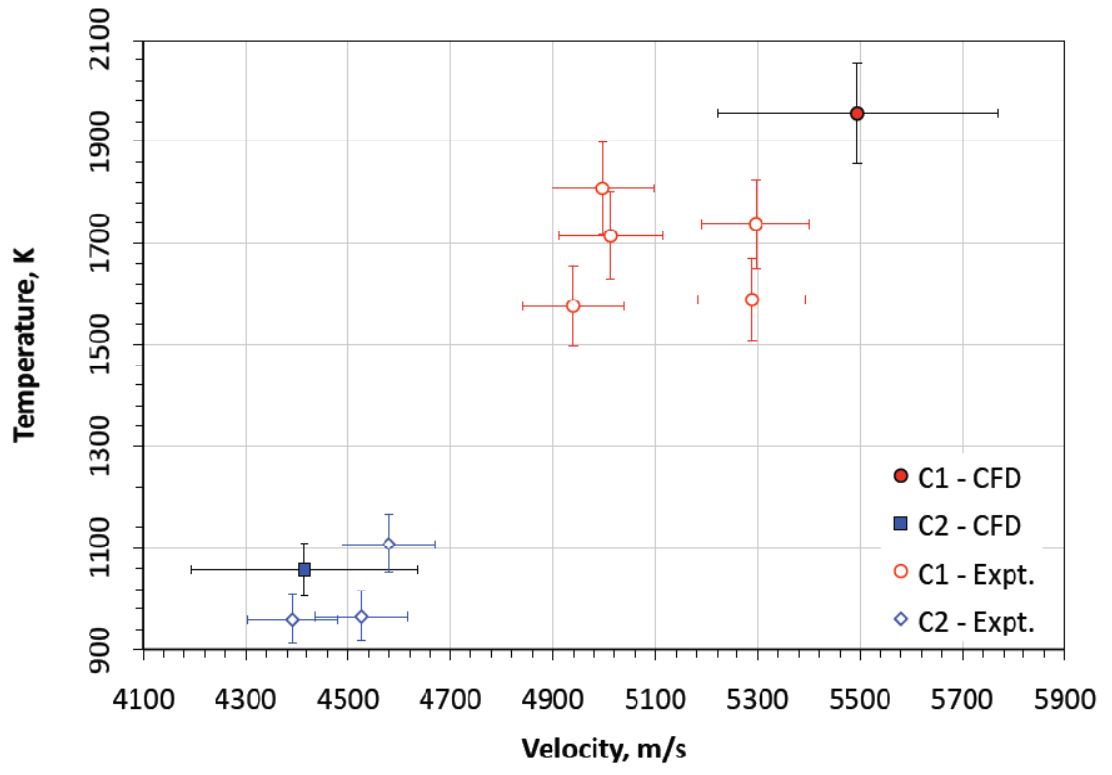

Figure 16: Translational temperature vs. gas velocity at the high (C1) and low (C2) enthalpy conditions at 10 inches distance to the nozzle exit, simulated by CFD and measured with TALIF. 


\section{Summary and Conclusions}

Emission spectra measured in the free stream of the NASA Ames Interaction Heating Facility showed strong emission of different electronic systems of $\mathrm{NO}$ in the UV wavelength region and of the $\mathrm{N}_{2} \mathrm{~B}-\mathrm{A}$ transition $\left(1^{\text {st }}\right.$ Positive system) in the VIS-NIR. Comparing spectra simulated using a combination of DPLR (CFD) and NEQAIR (line-by-line radiation) and experimental measurements the following observations are made:

1. The electronic excitation temperatures of $4200 \mathrm{~K}$ for $\mathrm{N}_{2}$ and $9000 \mathrm{~K}$ for $\mathrm{NO}$, required to match the magnitude of the measured spectra, are significantly different from each other and from the value of $\approx 3200 \mathrm{~K}$ (common to $\mathrm{N}_{2}$ and NO) obtained from DPLR simulations of the flow in the nozzle and free jet. It is hypothesized that both this disagreement between predicted and measured temperatures, and the differences between $\mathrm{N}_{2}$ and $\mathrm{NO}$, are at least partly due to significant population of the upper electronic states of the molecules through chemical processes.

2. For the case of NO, overpopulation is partly caused by excited state chemistry (in the form of recombination of atoms into electronically excited states of NO) or by NO molecules produced through the Zel'dovich reaction $\mathrm{N}_{2}+\mathrm{O}->\mathrm{NO}+\mathrm{N}$. This aspect is currently being investigated through more tests.

3. The shapes of the observed $\mathrm{N}_{2}$ spectral bands strongly disagree with NEQAIR simulation spectra based on thermal excitation alone. The measured spectra could be fitted only if the electronic-vibrational transitions were computed separately for each upper vibrational level and then scaled individually. Populations of the upper vibrational levels of the $\mathrm{N}_{2} \mathrm{~B}$ state were found by applying the scaling factors to the populations used in NEQAIR. Compared to a Boltzmann distribution (used in NEQAIR), the population distributions estimated using scaling factors were significantly higher, and the distribution peaked at $\mathrm{v}_{\text {upper }}=13$. This peak was explained by inverse pre-dissociation.

4. A zero-order approach for estimating nitrogen atom particle densities from the $\mathrm{N}_{2} \mathrm{~B}$ populations at high vibrational levels was derived by estimating contributions to population changes based on general assumptions and comparison of CFD and experimental data.

5. At the conditions investigated here, the population process of the $\mathrm{N}_{2} \mathrm{~B}$ state at high vibrational levels is considered to be dominated by radiative transitions (populating $\mathrm{N}_{2} \mathrm{C}-\mathrm{B}$ transition, depopulation $\mathrm{N}_{2}$ B-A which both are measured), quenching through heavy particle collisions, and population through inverse predissociation. The contribution of quenching cannot easily be estimated but the lower bound for atom concentrations can be obtained if no quenching is considered. An upper bound could be obtained if every heavy particle collision with a $\mathrm{N}_{2} \mathrm{~B}$ state molecule is assumed to result in depopulation. For the case of no quenching, the square of atom particle concentration is directly proportional to the photon balance of the two transitions involved divided by the rate coefficients for the inverse pre-dissociation process. As soon as these rate coefficients are available first estimates of atom particle densities will be derived from these measurements.

For future work, the analysis of $\mathrm{N}_{2}$ will be done for $\mathrm{NO}$ as well, which will give access to both oxygen and nitrogen atom particle densities as soon as the corresponding rate coefficients are available. The results will be compared to TALIF measurements of atom particle concentrations at the same conditions, thus providing an anchoring of the emission spectroscopic results and the analysis method proposed here.

\section{Acknowledgments}

The present work was supported by NASA Contracts NAS2-03/44 to UARC, UC Santa Cruz, NNA04BC25C to ELORET Corporation, NNA10DE12C to ERC Inc., and by the NASA-SCAP (Strategic Capabilities Assets Program) which provided critical financial support of the arc jet operational capability at Ames. The authors would like to thank Dr. George Raiche (Chief, Thermophysics Facilities Branch, NASA ARC) for generously providing test time in the IHF facility for the experiment, and Dr. Aga Goodsell (Chief, Reacting Flow Environments Branch, NASA ARC) for support of modeling and simulation aspects of the present work. Furthermore, the authors wish to acknowledge the support Jay Grinstead, Vince Meglio, Imelda Terrazas-Salinas, Enrique Carballo, and thank the arc jet crew for their professional and tireless effort to maintain and operate the arc jets under demanding schedule pressures. 


\section{References}

1 Michael W. Winter, Dinesh K. Prabhu, Jaswinder S. Taunk, and Imelda Terrazas-Salinas, "Emission Spectroscopic Measurements in the Plenum of the NASA IHF Arc Jet Facility," $10^{\text {th }}$ AIAA/ASME Joint Thermophysics and Heat Transfer Conference, Chicago, IL, 28 Jun - 1 Jul 2010.

2 Jose A. Santos, Anuscheh Nawaz, Ed Martinez, and Imelda Terrazas-Salinas, "Volumetric Heat Flux Characterization Experiments in the Interaction Heating Facility at NASA Ames," AIAA 2010-4785, $10^{\text {th }}$ AIAA/ASME Joint Thermophysics and Heat Transfer Conference, 28 June - 1 July 2010, Chicago, Illinois.

3 Grinstead, J. H., Porter, B. J, and Carballo, J. E., "Flow Property Measurement Using Laser-induced Fluorescence in the NASA Ames Interaction Heating Facility," AIAA Paper 2011-1091, AIAA Aerospace Sciences Meeting, Orlando, FL, January 2011.

4 Prabhu, D K, et al., "CFD Analysis Framework for Arc-Heated Flowfields, I: Stagnation Testing in Arc-jets at NASA ARC," AIAA Paper AIAA-2009-4080, $41^{\text {st }}$ Thermophysics Conference, June 22-25, 2009, San Antonio, TX.

5 Wright, M J, Candler, G V, and Bose, D, "Data-Parallel Line Relaxation Method of the Navier-Stokes Equations," AIAA Journal, Vol. 36, No. 9, 1998, pp. 1603-1609.

6 Whiting, E E, Park, C, Liu, Y, Arnold, J O, and Paterson, J A, "NEQAIR96, Nonequilibrium and Equilibrium Radiative Transport and Spectra Program: User's Manual," NASA RP-1389, NASA, December 1996.

7 Seong-Yoon Hyun , Chul Park, and Keun-Shik Chang, "Rate Parameters for Electronic Excitation of Diatomic Molecules, 4. NO Radiation," AIAA 2009-1595, 47th AIAA Aerospace Sciences Meeting Including The New Horizons Forum and Aerospace Exposition, 5 - 8 January 2009, Orlando, Florida.

8 Babikian, D. S., Gopaul, N. K. J. L., and Park, C., "Measurement and Analysis of Nitric Oxide Radiation in an Arcjet flow," Journal of Thermophysics and Heat Transfer, Vol. 8, No. 4, October-December 1994, pp. 737743.

9 Park, C. S., Newfield, M. E., Fletcher, D. G., Gökcen, T., and Sharma, S. P., "Spectroscopic Emission Measurements Within the Blunt-Body Shock Layer in an Arcjet Flow," Journal of Thermophysics and Heat Transfer, Vol. 12, No. 2, April-June 1998, pp. 190-197.

10 Park, C. S., Newfield, M. E., Fletcher, D. G., and Gökcen, T., "Spectroscopic Measurements of Shock-Layer Flows in an Arcjet Facility," Journal of Thermophysics and Heat Transfer, Vol. 13, No. 1, January-March 1999, pp. 60-67.

11 R. J. Gessman, C. O. Laux, and C. H. Kruger, "Experimental study of kinetic mechanisms of recombining atmospheric pressure air plasmas," AIAA 97-2364, $28^{\text {th }}$ AIAA Plasmadynamics and Lasers Conference, Atlanta, GA, 1997.

12 Laux, C. O., "Radiation and nonequilibrium collisional-radiative models" in "Physico-chemical Models for High Enthalpy and Plasma Flows, VKI LS 2002-07, edited by D. G. Fletcher et al., Rhode-Saint-Genèse, Belgium, 2002.

13 Pierrot, L., L. Yu, R. J. Gessman, C. O. Laux, and C. H. Kruger, "Collisional-radiative modeling of nonequilibrium effects in nitrogen plasmas," AIAA 99-3478, 30th AIAA Plasmadynamics and Lasers Conference, Norfolk, VA, 1999.

14 Golde, M. F., and Thrush, B. A., “Afterglows,” Rep. Prog. Phys. 1973, volume 36, pp 1285-1364, 1973.

15 Becker, K. H., Fink, E. H., Groth, W., Jud, W., and Kley, D., "N2 formation in the Lewis-Rayleigh afterglow," Faraday Discussions of the Chemical Society, volume 53, pp35-51, 1972.

16 Harry Partridge, Stephen R. Langhoff, and Charles W. Bauschlicher, Jr., and David W. Schwenke, "Theoretical study of the $\mathrm{A}^{5} \Sigma_{\mathrm{g}}{ }^{+}$and $\mathrm{C}^{, " 5} \Pi_{\mathrm{u}}$ states of $\mathrm{N}_{2}$ : Implications for the $\mathrm{N}_{2}$ afterglow," J. Chern. Phys. 88 (5), 1 March 1988.

17 Gilmore, F.R., Laher, R.R., and Espy, P.J., "Frank-Condon factors, r-centeroids, electronic transition moments, and Einstein coefficients for many nitrogen and oxygen band systems," J. Phys. Chem. Ref. Data, 21, 1005-1107, 1992. 